\title{
MATHEMATICS FOR ENGINEERS
}

Lezioni di Analisi Matematica. By Guido Fubini. Torino, Società Tipografico-Editrice Nazionale, 1923. viii $+470 \mathrm{pp}$.

Grundriss der Differential Rechnung. By Ludwig Kiepert. Hannover, Helwingsche Verlagsbuchhandlung, 1923. viii +348 pp. II. Band: Einige grundlegende Untersuchungen aus der Algebra und Funktionen von mehreren unabhängigen Veränderlichen.

Both of these books were written primarily for engineering and technical students. The former follows the course as given in the Polytechnic school at Turin, and the latter is written by a trained engineer for engineering students. It has been remarked so often that our scientific students do not know enough mathematics to enable them to go very far; particularly is this true of our physicists and engineers. A $\mathrm{Ph}$. D. in chemistry complains that he cannot read beyond the first hundred pages of Sommerfeld's Structure of the Atom and Spectral Lines, because there is too much mathematics. How far this is true may be judged by comparing the mathematical equipment of the above courses with one obtained in a calculus course in an American university.

The present edition of the first book is the fourth; previous editions appeared in 1913, 1915, 1920, which indicates its wide use in Italy. The difference in content between these texts and our American texts is not so marked. There is perhaps a greater emphasis on applications of calculus to algebraic problems in these foreign books, but the chief difference is in the point of view.

It is rather strange that we should be laboring under severe handicaps in the teaching of the pivotal course of our mathematical curriculum, the calculus. Our difficulties are two-fold. First, there is in vogue, what I may call the "double standard" amongst us. Mathematicians of repute will not hesitate to pursue a policy in their teaching which amounts to keeping their right hands in ignorance of what their left hands are doing. Two examples will illustrate this difficulty. An author of a calculus text writes in a footnote that the equation in the paragraph above "to be strictly accurate" requires some modification. Again, how often do we find theorems stated as true, which in the proof make use of a uniformity condition, which bobs up serenely from nowhere, and which disappears again in applications to nowhere.

Our second difficulty is that too many of us bury our heads ostrichlike in the sand and keep the eyes of our students closed to the fundamental assumptions on which the basic principles of the course are founded. This tends to superficiality and the "hand-book" method 
of teaching the calculus. As a student, the reviewer recalls emerging from the first calculus course with no other knowledge of what it was all about than being able to differentiate $x^{3}$ and integrate $x^{2} d x$. Our first course does not go deeply enough into the facts.

If the "small zeros" of the engineer are ever to be banished from the face of the earth, it will be due to the fact that our teaching will from the very beginning have taught him the significance of relative size. No opportunity will be given him to form bad mathematical habits and to acquire erroneous ideas. No longer will we write equations whose only interpretation is "that one variable is approaching another variable as a limit".

It is quite a contrast to regard the first book, especially, that by Fubini, and to see what its bearing is on our situation. The author aims at the outset to set forth the fundamental notions of number, angle, area and volume. There are no extensive proofs given, but the facts are stated correctly and interestingly. There follows about 100 pages of algebra, principally the theory of equations, which an American student would normally acquire in his freshman or sophomore year. The remainder of the book deals with the usual topics of the calculus. The meaning of the principles is profusely illustrated by means of examples, taken chiefly from the field of mechanics on account of the future interest of the student. The formal work of differentiation is not given very much space, but all the essential formulas are developed. The applications of the derivative are the usual ones to curve sketching, indeterminate forms, multiple roots of an algebraic equation, maxima and minima and points of inflexion. The first and second laws of the mean for derivatives are proved.

The definite integrals, simple and multiple, are introduced by means of additive functions of a one-dimensional, two-dimensional, or threedimensional region, as the case may be. The proof for integrability is based on an argument which is very similar to the one given by the reviewer,* except that Fubini's theorem $t$ is not as general. His final result stated on page 329 requires uniformity and is equivalent to Osgood's ‘ form of Duhamel's theorem.

The latter half of the course includes what would be included in

* H. J. Ettlinger, A simple form of Duhamel's theorem and some new applications, American Mathematical Monthly, vol. 29 (1922), p. $246 \mathrm{ff}$. See also a paper by the reviewer, On the integrability of a continuous function, American Mathematical Monthly, vol. 31 (1924), p. 319.

$\dagger$ Cf. pp. 316-17 and footnote of the book under review.

$\$$ W. F. Osgood, The integral as a limit of a sum and a theorem of Duhamel's, Annals of Mathematics, (2), vol. 4 (1903), pp. 164-65. 
a course of advanced calculus in this country. The existence theorem due to Cauchy for differential equations is stated, but its proof is omitted. Space geometry, envelopes, line and surface integrals, transformation of a double integral, Fourier series, and functions of a complex variable are touched upon and treated to a slight extent in this part of the book.

There is one list of problems thirty-nine in number on pp. 55-61 for the chapter on theory of equations. The exercises in the rest of the book are few and far between. It is probably true that long lists of calculus problems are available for class use from other independent sources.

The printing of the book is unusually good; only two misprints have been noticed. On page 123, near the bottom of the page, the third term of the geometric progression should be $1 / 2^{2}$ instead of $1 / 3$. On page 170 , the term $1 / x$ is omitted from the formula for the derivative of $\log _{e^{x}}$.

The book by Kiepert deals with the applications of the calculus to algebra, particularly the solution of equations numerically to any required degree of approximation. In the latter half of the book, functions of several variables are treated with applications to space analytic geometry, including what is ordinarily included in differential geometry in this country.

Throughout the book the complete solution of a great many examples is given to illustrate the principles used. The last chapter is devoted to maxima and minima of functions of several variables. There is a summary of the important formulas proved in this volume at the end of the book.

The plan of both of these books commends itself very highly to those who are desirous of improving the teaching of the calculus not alone for those who use mathematics as a tool, but also for those whom we may look to as the future searchers after mathematical truth.

H. J. Etthinger 